\title{
Emission Characteristics and Risk Assessment in an Industrial Metropolitan Area in Taiwan using the AERMOD Model
}

\author{
Jiun-Horng Tsai and Wei-Ting Gu \\ National Cheng-Kung University, Department of Environmental Engineering, Tainan, Taiwan \\ Correspondence: Jiun-Horng Tsai (jhtsai@mail.ncku.edu.tw)
}

Received: 23 May 2019 - Revised: 19 August 2019 - Accepted: 21 August 2019 - Published: 19 September 2019

\begin{abstract}
Air toxics, also known as hazardous air pollutants (HAPs), have gained increased public awareness in recent years. Air toxics may be released from various sources, such as mobile sources, stationary sources, and fugitive emissions. This study investigated profiles of air toxics from mobile sources, stationary sources, and the operations in a port in an industrial metropolitan area in Taiwan. Six carcinogens, including benzene, formaldehyde, 1,3-butadiene, arsenic, 2,3,7,8-TCDD, and diesel particulate matter (DPM), were chosen as the target pollutants. The AERMOD model was applied to simulate the concentrations of the ambient air toxic species, and the concentrations were used to evaluate cancer risk. Cancer risk for each air toxic was also investigated to evaluate the potential impact on residents. The results of the emission estimation for the base year (2014) showed that the emissions of benzene, 1,3-butadiene, and formaldehyde could be mainly attributed to mobile sources in the study areas. The contributions, in order, were $86 \%$, $77 \%$, and $69 \%$. DPM emissions from port operations accounted for $76 \%$, and most of the arsenic (70\%) and 2,3,7,8TCDD $(99 \%)$ were emitted from stationary sources, especially from the steel industry. Approximately $66 \%$ and $32 \%$ of the cancer risk of air toxics were contributed to the emissions from port operations and on-road vehicles, respectively, in this area, and approximately $1.4 \%$ of the risk was contributed to stationary sources. DPM was the pollutant that posed the highest cancer risk among all six air toxics. It accounted for more than $80 \%$ of the overall cancer risk, followed by 1,3 -butadiene $(10 \%)$, benzene $(4.7 \%)$, formaldehyde $(1.2 \%)$, arsenic $(0.7 \%)$, and 2,3,7,8-TCDD (0.2\%). The dominant sources of DPM were ocean-going vessels and diesel trucks.
\end{abstract}

\section{Introduction}

Air toxics, also known as hazardous air pollutants (HAPs), have gained more public attention in recent years. Air toxics may be released from various sources, including mobile sources, stationary sources, and fugitive emissions.

Most species are identified as Group 1 human carcinogens by the International Agency for Research on Cancer (IARC) and are of concern to both people and the government (IARC, 2019). Parts of the VOCs are harmful to humans and cause eye and skin irritation, and are harmful to the bronchus. Even more serious, some of them, such as benzene, formaldehyde, 1,3-butadiene, arsenic species, 2,3,7,8TCDD, and diesel particulate matter (DPM) are carcinogenic (IARC, 1997, 2019).

This study investigated the profiles of air toxics from mobile sources, stationary sources, and activities in a port in an industrial metropolitan area. The cancer risk for each air toxic and each emission source was also evaluated. Six species of carcinogenic pollutants, including benzene, formaldehyde, 1,3-butadiene, arsenic, 2,3,7,8-TCDD, and diesel particulate matter (DPM), were selected as the target pollutants. Ambient concentrations of each of them from various sources were simulated using the AERMOS model along with a GIS (geographic information system) to present the spatial distribution of the airborne concentrations. A cancer risk assessment was also conducted to evaluate the potential impacts on employee and residents in this industrial metropolitan region. 


\section{Characteristics of the target pollutants}

Benzene can be present in the petrochemical industry, the coking of coal, production of toluene, xylene, and other aromatic compounds, and is a widely used industrial solvent. In addition, motor mobile exhaust is an important source of benzene in the environment (WHO, 2010). Formaldehyde is an organic base chemical and is applied in industry. Parts of formaldehyde are emitted from the phenol-formaldehyde produced in industry and the low-cost urea-formaldehyde resin synthesis used in bonding wood. Formaldehyde can thus be released from building materials, furniture, and household products into the indoor air (Salthammer, 2013). $2,3,7,8$-TCDD (2,3,7,8-Tetrachlorodibenzo-p-dioxin) is a by-product from the incomplete combustion of such things as fossil fuels, biomass, and municipal and industrial waste combustion that is released into the environment. In human studies, it has been shown that soft-tissue sarcomas, lymphomas, and stomach carcinomas may be associated with exposure to 2,3,7,8-TCDD. In the case of 1,3-butadiene, the main air emissions sources are on-road and off road mobile emissions ( $47 \%$ and $35 \%$, respectively), biomass burning $(16 \%)$, butadiene users $(1.2 \%)$, and petroleum refining $(0.2 \%)$ in the US (US EPA, 1996). These diesel exhaust particulate matters can induce cytokine/chemokine responses, inflammation in cytokines, cellular oxidative stress, and mutations in human and hamster hybrid cells (Bao et al., 2007; Mazzarella et al., 2007; Øvrevik et al., 2010). Epidemiological studies have shown that an increase in particulate matter levels is associated with an increase in adverse cardiopulmonary effects (HEI, 2003; Pope III, 2004). Arsenic species can be emitted from human activities, such as coal burning, industrial waste disposal, the application of agricultural chemicals containing arsenic (such as insecticides, herbicides, algicides, and growth promoters), or the burning of wood treated with arsenic-containing preservatives (Environment Agency, 2008).

\section{Materials and Method}

\subsection{Selected area}

Xiaogang District in Kaohsiung, the second largest city in Taiwan, was selected as the target location. The population was approximately 156000 , and the population density was over 3400 people $\mathrm{km}^{-2}$ in Xiaogang District during the study period. There are complex emission sources, including a heavy industrial district (the iron and steel industry, refinery plant, chemical industry, and a ship building company, among others), the Kaohsiung port area, motor vehicles, and an airport. The main emission sources in Xiaogang District are shown Fig. 1.

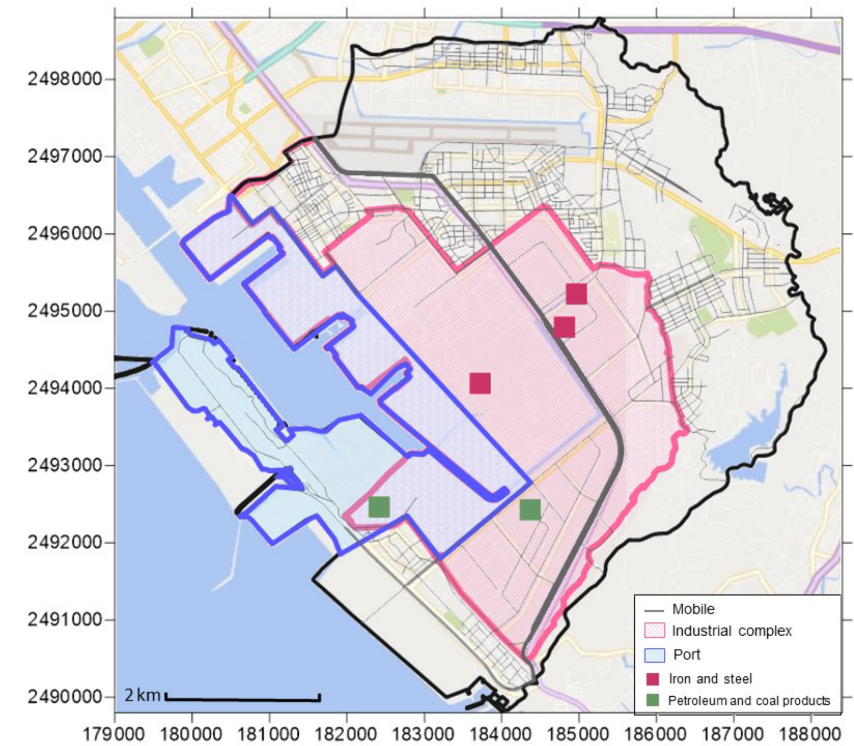

Figure 1. Major airborne emission sources in Xiaogang District (Map coordinates: longitude and latitude).

\subsection{Source database}

The environmental health impact in this study was conducted using emission estimations, an ambient concentration simulation, and a cancer risk calculation. The emissions from on-road mobile sources, stationary sources, and port operations were calculated using the emission factor and activity of each source (KEPA, 2015). On-road mobile sources included gasoline and diesel vehicles. Stationary sources included stack and fugitive emissions in the industrial complex. For stationary sources, over 50 industrial plants and 550 processes were selected to determine the emissions in Xiaogang District. The port operations included vessels, service equipment, and non-road engines/on-road vehicles inside the port area. The Taiwan Emission Data System (TEDs 8.0) was employed to determine the emissions (TEPA, 2019). The emission factors for each air toxic were derived from the SPECIATE 4.4 database, which was developed by the US EPA (US EPA, 2014). According to the Taiwan Emission Data System (TEDs), the emission data estimation uncertainty was identified as being between class B (the variation was $\pm 20 \%-$ $60 \%$ ) and Class $C$ (the variation was $\pm 50 \%-150 \%$ ) (TEPA, 2019).

\subsection{Scenarios}

Four emission scenarios were evaluated in this study, including a basic case and three controlled cases. The basic case scenario represented the emissions in the base year (2014). Scenario 1 was the permitted emissions from stationary sources. Scenario 2 represented the business as usual (BAU) situation. Scenario 3 represented the controlled emissions 

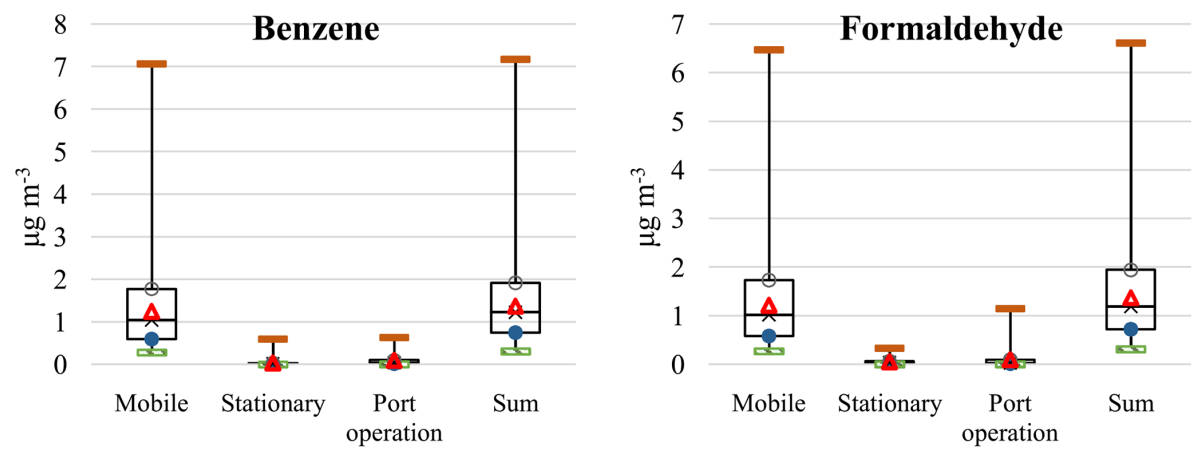

-MIN •Q1 XMEDIAN OQ3 - MAX $\triangle$ MEAN
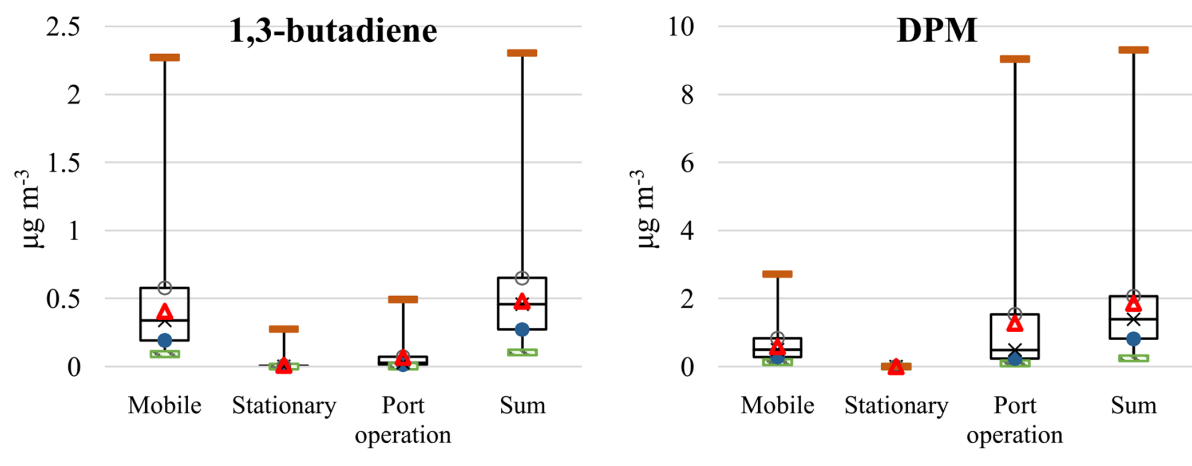

-MIN $\bullet$ Q1 $\times$ MEDIAN OQ3 - MAX $\triangle$ MEAN

- MIN $\bullet$ Q1 $\times$ MEDIAN OQ3 - MAX $\triangle$ MEAN
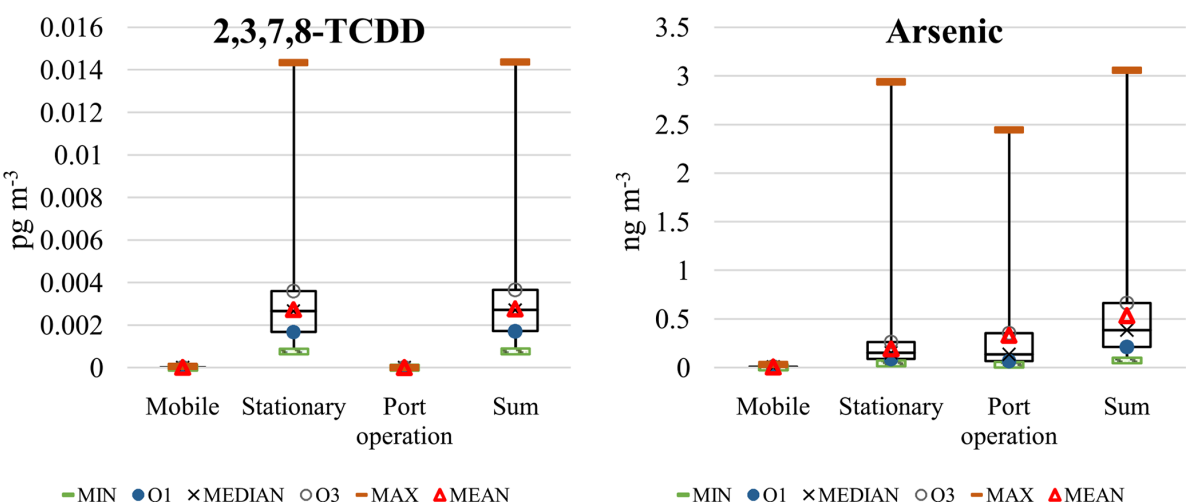

-MIN $\bullet$ Q1 $\times$ MEDIAN OQ3 - MAX $\triangle$ MEAN

Figure 2. Incremental concentrations due to various emission sources.

based on enforcing control measures designed in an air pollution prevention plan. The baseline scenario emissions of benzene, formaldehyde, 1,3-butadiene, arsenic, and DPM were $184482,227334,67957,238$, and $316036 \mathrm{~kg} \mathrm{yr}^{-1}$, respectively, and 2,3,7,8-TCDD was $4994 \mathrm{mg}^{-T E Q ~} \mathrm{yr}^{-1}$. Scenario two was the permitted emissions for stationary sources, followed by the mobile and port operation emissions scenario. The benzene emissions were $204383 \mathrm{~kg} \mathrm{yr}^{-1}$, formaldehyde was $518824 \mathrm{~kg} \mathrm{yr}^{-1}, 1,3$-butadiene was $69001 \mathrm{~kg} \mathrm{yr}^{-1}$, arsenic was $53150 \mathrm{~kg} \mathrm{yr}^{-1}$, and DPM was $316037 \mathrm{~kg} \mathrm{yr}^{-1}$, and 2,3,7,8-TCDD was $4994 \mathrm{mg}^{-T E Q ~} \mathrm{yr}^{-1}$. The permitted emissions were mainly from stationary sources.

Scenario 3 did not involve the use of any control strategy or the growth in economic development. The emissions of benzene, formaldehyde, 1,3-butadiene, arsenic, and DPM were $116395,166821,46443,236$, and $286928 \mathrm{~kg} \mathrm{yr}^{-1}$, respectively, and those for $2,3,7,8$-TCDD were $5059 \mathrm{mg}$ ${\mathrm{TEQ} \mathrm{yr}^{-1}}^{-1}$. The presence of new vehicles was main reason for reductions in emissions. Scenario 4 was conducted for the control measures intended to reduce emissions, for which the benzene, formaldehyde, 1,3-butadiene, arsenic, and DPM emissions were 112 197, 138 463, 44 604, 140, and $269559 \mathrm{~kg} \mathrm{yr}^{-1}$, respectively, and those for $2,3,7,8-\mathrm{TCDD}$ were $5059 \mathrm{mg}^{-}$TEQ $\mathrm{yr}^{-1}$. 
(a) Mobile

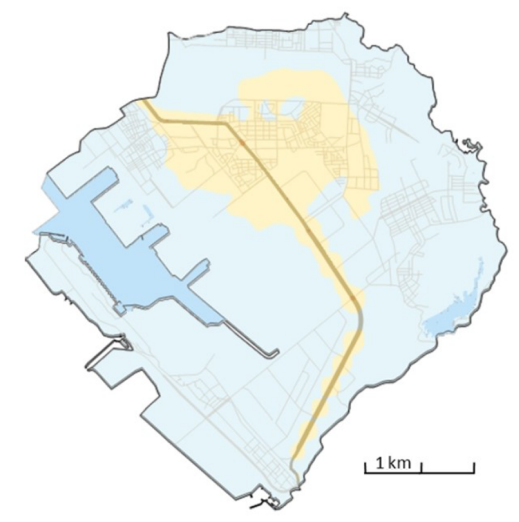

(c) Port

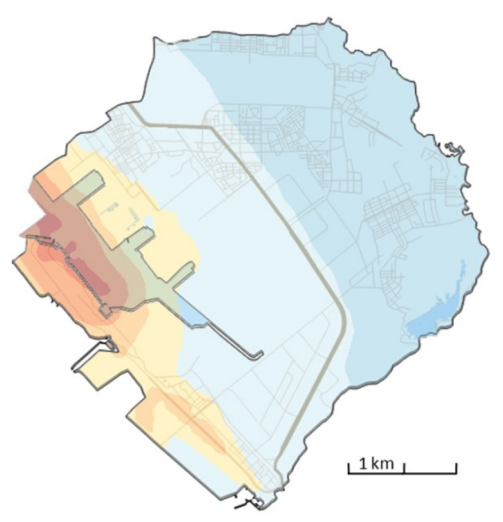

(b) Stationary

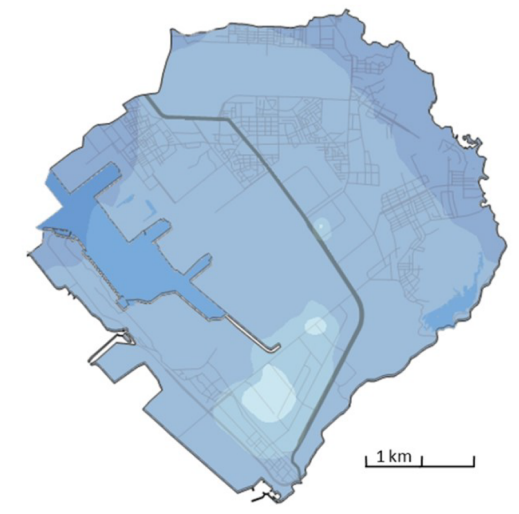

(d) Total

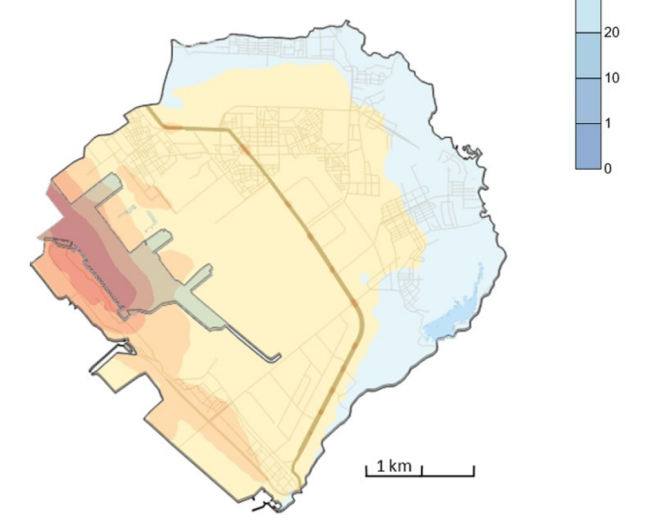

Figure 3. Spatial distribution of carcinogenic risk among all sources.

Table 1. Emissions of hazardous air pollutants $\left(\mathrm{kg} \mathrm{yr}^{-1}\right)$ from various sources.

\begin{tabular}{|c|c|c|c|c|c|c|}
\hline Source & Benzene & Formaldehyde & 1,3-butadiene & Arsenic & $\mathrm{DPM}$ & $\begin{array}{r}2,3,7,8 \mathrm{TCDD} \\
\left(\mathrm{mg}^{-\mathrm{TEQ}} \mathrm{yr}^{-1}\right)\end{array}$ \\
\hline Mobile sources & $159288(86.3)^{*}$ & $156223(68.7)$ & $51992(77)$ & $0.88(0.37)$ & $75906(24)$ & $0.98(0.02)$ \\
\hline Stationary sources & $8122(4.4)$ & $59496(26.2)$ & $1320(2)$ & $166(69.8)$ & 0 & 4993 (99.979) \\
\hline Port operations & $17072(9.3)$ & $11615(5.1)$ & $14644(22)$ & $71 \quad(29.8)$ & $240131(76)$ & $0.05(0.001)$ \\
\hline Sum & 184482 & 227334 & 67957 & 238 & 316036 & 4994 \\
\hline
\end{tabular}

* Contribution fraction $(\%)$.

The Gaussian dispersion model (AERMOD) (USEPA, 2004) was used to simulate the ambient concentration of the target air toxics in this area. Potential cancer risk and the cancer burden for each air toxic were evaluated by following a protocol developed by the California OEHHA (OEHHA, 2016). To evaluate the efficacy of the models, the following performance measures were applied in this study. Some parameters, including fractional bias $(-0.5 \leq \mathrm{FB} \leq 0.5)$, normalized mean square error (NMSE $\leq 0.5$ ), coefficient of correlation $(R \approx 1)$, and factor of two $\left(\mathrm{Fa}_{2} \geq 0.8\right)$, were conducted to ensure the results of the model simulation were acceptable (Kumar et al., 2006).

\section{Results and Discussion}

\subsection{Emission Characteristics}

The criteria for the air pollutant emission data were obtained from TEDs 8.0. The results indicated that the $\mathrm{PM}_{2.5}, \mathrm{SO}_{x}$, $\mathrm{NO}_{x}$, and total hydrocarbon emissions were 2400 (42\% of Kaohsiung), 22500 (76\% of Kaohsiung), 19000 (40\% of Kaohsiung) and 6300 (10\% of Kaohsiung) ton $\mathrm{yr}^{-1}$, respectively, in Xiaogang District. The emissions of $\mathrm{PM}_{2.5}, \mathrm{NO}_{x}$, and total hydrocarbon in Kaohsiung could be $7.3 \%-10 \%$ fraction of Taiwan, and the $\mathrm{SO}_{x}$ emission fraction was over $20 \%$ higher than that of Taiwan. 
Table 2. Cancer risk from different emission sources and species for different percentile concentrations.

\begin{tabular}{|c|c|c|c|c|c|}
\hline Species & $\begin{array}{l}\text { Concentration } \\
\text { percentile }\end{array}$ & $\begin{array}{r}\text { Mobile sources } \\
\qquad\left(\times 10^{-6}\right)\end{array}$ & $\begin{array}{r}\text { Stationary sources } \\
\left(\times 10^{-6}\right)\end{array}$ & $\begin{array}{r}\text { Port operations } \\
\qquad\left(\times 10^{-6}\right)\end{array}$ & $\begin{array}{r}\text { Sum } \\
\left(\times 10^{-6}\right)\end{array}$ \\
\hline \multirow{4}{*}{ Benzene } & $50 \%$ & 26.2 & 0.368 & 0.916 & 30.8 \\
\hline & $75 \%$ & 44.6 & 0.779 & 2.53 & 48.2 \\
\hline & $90 \%$ & 58.4 & 1.63 & 6.24 & 60.1 \\
\hline & $99 \%$ & 79.8 & 4.94 & 14.1 & 81.1 \\
\hline \multirow{4}{*}{ Formaldehyde } & $50 \%$ & 5.38 & 0.210 & 0.139 & 6.29 \\
\hline & $75 \%$ & 9.16 & 0.329 & 0.507 & 10.3 \\
\hline & $90 \%$ & 12.0 & 0.475 & 1.46 & 12.8 \\
\hline & $99 \%$ & 16.0 & 0.845 & 4.34 & 16.6 \\
\hline \multirow{4}{*}{ 1,3-Butadiene } & $50 \%$ & 51.2 & 0.432 & 4.18 & 69.2 \\
\hline & $75 \%$ & 87.3 & 1.00 & 10.9 & 98.3 \\
\hline & $90 \%$ & 114 & 2.84 & 27.9 & 118 \\
\hline & $99 \%$ & 156 & 12.1 & 65.2 & 160 \\
\hline \multirow{4}{*}{ Arsenic } & $50 \%$ & 0.0173 & 0.458 & 0.408 & 1.16 \\
\hline & $75 \%$ & 0.0292 & 0.790 & 1.07 & 2.00 \\
\hline & $90 \%$ & 0.0384 & 1.13 & 2.74 & 3.40 \\
\hline & $99 \%$ & 0.0507 & 1.77 & 6.45 & 6.82 \\
\hline \multirow{4}{*}{ DPM } & $50 \%$ & 137 & - & 135 & 385 \\
\hline & $75 \%$ & 231 & - & 425 & 572 \\
\hline & $90 \%$ & 304 & - & 1000 & 1130 \\
\hline & $99 \%$ & 401 & - & 1960 & 2040 \\
\hline \multirow{4}{*}{$2,3,7,8-\mathrm{TCDD}$} & $50 \%$ & $3.27 \times 10^{-4}$ & 0.0870 & - & $8.87 \times 10^{-2}$ \\
\hline & $75 \%$ & $3.27 \times 10^{-4}$ & 0.117 & - & 0.119 \\
\hline & $90 \%$ & $3.27 \times 10^{-4}$ & 0.135 & - & 0.136 \\
\hline & $99 \%$ & $6.54 \times 10^{-4}$ & 0.219 & - & 0.222 \\
\hline \multirow{4}{*}{ Sum } & $50 \%$ & 220 & 1.55 & 141 & 493 \\
\hline & $75 \%$ & 372 & 3.02 & 440 & 731 \\
\hline & $90 \%$ & 489 & 6.20 & 1040 & 1330 \\
\hline & $99 \%$ & 652 & 19.9 & 2005 & 2310 \\
\hline
\end{tabular}

The emissions of six hazardous air pollutants from various sources are shown in Table 1 . The results indicated that the emissions of benzene, formaldehyde, 1,3-butadiene, arsenic and DPM were 184482, 227334, 67957, 238, and $316036 \mathrm{~kg} \mathrm{yr}^{-1}$, respectively, and those for 2,3,7,8-TCDD

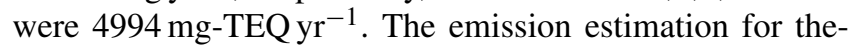
six target air toxics showed that on-road mobile sources dominated the emissions of benzene $(86.3 \%)$, formaldehyde $(68.7 \%)$, and 1,3-butadiene $(77 \%)$ in the study areas. Arsenic (69.8\%) and 2,3,7,8-TCDD (almost 100\%) were mainly emitted from stationary sources. Most of the DPM was emitted from diesel engines, port operations, and oceangoing vessels.

\subsection{Concentration increments based on AERMOD}

Figure 2 shows the air toxics concentrations obtained using the AERMOD stimulation. The highest Benzene concentration increments were $7.06,0.596$, and $0.63 \mu \mathrm{g} \mathrm{m}^{-3}$ from the mobile sources, stationary sources, and port operations, respectively. The highest Formaldehyde concentration increments were $6.47,1.14$, and $0.328 \mu \mathrm{g} \mathrm{m}^{-3}$ from the mobile sources, port operations, and stationary structures, respectively.

The highest 1,3-butadiene concentration increments were $2.27,0.49$ and $0.28 \mu \mathrm{g} \mathrm{m}^{-3}$ for the mobile sources, port operations, and stationary sources, respectively. For arsenic, the highest concentration increments were 2.94, 2.45, and $0.032 \mathrm{ng} \mathrm{m}^{-3}$ from the stationary sources, port operations, and mobile sources, respectively.

The highest DMP concentration increments were 9.03 and $2.71 \mathrm{~g} \mathrm{~m}^{-3}$ from port operations and mobile sources, respectively. For 2,3,7,8-TCDD, the stationary sources and mobile sources contributed to increases of 0.01433 and $0.00006 \mathrm{pg} \mathrm{m}^{-3}$, respectively.

Spatial air toxics distribution indicated a high concentration of DMP, benzene, formaldehyde, and 1.3-butadiene on 
the highways and downtown are as due to their high traffic loading.

\subsection{Cancer risk analysis}

The spatial distribution of cancer risk is presented in Fig. 3 . The cancer risk for DMP, benzene, formaldehyde and 1,3butadine from mobile, and DMP, and 1,3-butadine was over $10^{-6}$ at the $50 \%$ percentile concentration. The cancer risk was mainly from the mobile sources and port operation in Xiaogang District. At the $90 \%$ percentile concentration, the cancer risk of most air toxic species from different sources were higher than $10^{-6}$, with the exception of 2,3,7,8-TCDD, arsenic from stationary sources, and DPM from stationary sources. The total cancer risk for the six species from the three sources could reach $4.93 \times 10^{-4}$ and $1.33 \times 10^{-3}$ at $50 \%$ and $90 \%$ percentile concentrations, respectively (shown as Table 2).

The results of the cancer risk assessment indicated that DPM posed the highest risk among the six air toxics. DPM contributed more than $80 \%$ of the total cancer risk, followed by 1,3-butadiene, benzene, formaldehyde, arsenic, and 2,3,7,8-TCDD. In the industrial area, most (around 99\%) cancer risk would be contributed by the air toxics emitted from on-road vehicles and port operations. Cancer risk caused by stationary sources would be much less than those caused by all mobile sources.

The effects of regulations on mobile sources, emissions of benzene, formaldehyde, 1,3-butadiene would decrease these risks significantly. Emission of DPM both from onroad trucks and vessel emissions would also be decreased by around $10 \%$. No significant variations in emissions of arsenic and 2,3,7,8-TCDD would be expected.

The air model simulation results indicated that emission reduction of these target air toxics from mobile sources may improve the cancer burden of residents in the study area. Reducing DPM emissions from on-road diesel trucks could improve the cancer risk for residents along the transportation routes. However, control of the air toxics emissions from all sources in port operations and vessels could improve the cancer risk in the industrial metropolitan area.

\section{Conclusions}

The mobile sources were the main sources of benzene $(86.3 \%)$, formaldehyde $(68.7 \%)$, and 1,3-butadiene $(77 \%)$ in Xiaogang District. DPM was emitted from diesel engines (mobile sources) and port operations. Stationary sources were the major sources of arsenic $(69.8 \%)$ and 2,3,7,8TCDD (approximately $100 \%$ ). The cancer risk caused by the various sources in the industrial metropolitan area indicated that the potential risk may be caused by DPM $>1,3$ butadiene $>$ benzene $>$ formaldehyde $>$ arsenic $>2,3,7,8$ -

TCDD. In total, the cancer risk from the six species from the three sources could reach $4.93 \times 10^{-4}$ and $1.33 \times 10^{-3}$ at the $50 \%$ and $90 \%$ percentile concentrations, respectively. DPM was found to be the most important carcinogenic pollutant in the study area. DPM from on-road trucks, diesel engines in port operations, and ocean-going vessels was the most important air toxic component, which potentially imposed high risks for residents and employees in these areas.

Data availability. The emission data of air toxics do not open to the public without permission.

Author contributions. JHT was the principal investigator of this research project. He designed the study work and overview all data. WTG was research assistant in this project. She did the emission estimation and modeling work.

Competing interests. The authors declare that they have no conflict of interest.

Special issue statement. This article is part of the special issue "European Geosciences Union General Assembly 2019, EGU Division Energy, Resources \& Environment (ERE)". It is a result of the EGU General Assembly 2019, Vienna, Austria, 7-12 April 2019.

Acknowledgements. The authors express their sincere thanks to H.L. Chiang for his advice and comments.

Financial support. This research was supported by the Ministry of Science \& Technology, Executive Yuan, Republic of China (Taiwan) for research fund support (MOST 104-2221-E-006-020MY3).

Review statement. This paper was edited by Christopher Juhlin and reviewed by two anonymous referees.

\section{References}

Bao, L., Chen, S., Wu, L., Hei, T. K., Wu, Y., Yu, Z., and Xu, A.: Mutagenicity of diesel exhaust particles mediated by cellparticle interaction in mammalian cells, Toxicology, 229, 91100, https://doi.org/10.1016/j.tox.2006.10.007, 2007.

Environment Agency.: A review of the toxicity of arsenic in air, Science Report, SC020104/SR4, Bristol, UK, 2008.

HEI (Health Effects Institute): Revised Analyses of Time-Series Studies of Air Pollution and Health, Special Report, Health Effects Institute, Boston, 2003.

International Agency for Research on Cancer (IARC): Monographs, "Benzene", 29, 93-148, 391-398, 1997. 
International Agency for Research on Cancer (IARC): Monographs on the identification of carcinogenic hazards to humans, https: //monographs.iarc.fr/agents-classified-by-the-iarc/, last access: May, 2019.

Kaohsiung Environmental Protection Agency (KEPA): Kaohsiung State Implementation Plan, Kaohsiung, Taiwan, 2015.

Kumar, A., Dixit, S., Varadarajan, C., Vijayan, A., and Masuraha, A.: Evaluation of the AERMOD Dispersion Model as a Function of Atmospheric Stability for an Urban Area, Environ. Progr., 25, 141-151, 2006.

Mazzarella, G., Ferraraccio, F., Prati, M. V., Annuniziata, S., Bianco, A., Mezzogiorno, A., Liguori, G., Angelillo, I. F., and Cazzola, M.: Effect of diesel exhaust particles on human lung epithelial cells: an in vitro study, Resp. Med., 101, 1155-1162, https://doi.org/10.1016/j.rmed.2006.11.011, 2007.

OEHHA: Air Toxics Hot Spots Program Risk Assessment Guidelines, https://oehha.ca.gov/air/air-toxics-hot-spots, last access: March, 2016.

Øvrevik, J., Arlt, V. M., Øуa, E., Nagy, E., Mollerup, S., Phillips, D. H., Lag, M., and Holme, J. A.: Different effects of nitro-PAHs and amino-PAHs on cytokine and chemokine responses in human bronchial epithelial BEAS-2B cells, Toxicol. Appl. Pharmacol., 242, 270-280, https://doi.org/10.1016/j.taap.2009.10.017, 2010.
Pope III, C. A., Burnett, R. T., Thurston, G. D., Thun, M. J., Calle, E. E., and Krewski, D.: Cardiovascular mortality and long-term exposure to particulate air pollution, Circulation, 109, 71-77, https://doi.org/10.1161/01.CIR.0000108927.80044.7F, 2004.

Salthammer, T.: Formaldehyde in the Ambient Atmosphere: From an Indoor Pollutant to an Outdoor Pollutant?, Angew. Chem. Int. Edit., 52, 3320-3327, https://doi.org/10.1002/anie.201205984, 2013.

Taiwan Environmental Protection Agency (TEPA): Taiwan air pollutants emission data system, https://teds.epa.gov.tw/ Introduction.aspx, last access: 5 August 2019.

U. S. Environmental Protection Agency: Locating and Estimating Air Emissions from Sources of 1,3-Butadiene, EPA 454/R-96008, Eastern Research Group, North Carolina, 1996.

United States Environmental Protection Agency: Emissions Monitoring and Analysis Division, AERMOD: DESCRIPTION OF MODEL FORMULATION, Office of Air Quality Planning and Standards, Research Triangle Park, NC, Publication No. EPA454/R-03-004, 2004.

U.S. Environmental Protection Agency: SPECIATE Version 4.4 Database Development Documentation. Research Triangle Park, NC, EPA/600/R-13/307, 2014.

World Health Organization: Exposure to benzene: A major public health concern, Geneva 27, Switzerland, 2010. 